Supporting Information for

\title{
Thailandenes, cryptic polyene natural products isolated from Burkholderia thailandensis using phenotype-guided transposon mutagenesis
}

\author{
Jong-Duk Park ${ }^{1,6}$, Kyuho Moon ${ }^{1,6}$, Cheryl Miller ${ }^{2}$, Jessica Rose ${ }^{3}$, Fei Xu ${ }^{1}$, Christopher C. Ebmeier ${ }^{4}$, \\ Jeremy R. Jacobsen ${ }^{4}$, Dainan Mao, ${ }^{1}$ William M. Old ${ }^{4}$, David DeShazer ${ }^{5, *}$ \\ and Mohammad R. Seyedsayamdost ${ }^{1, *}$
}

\footnotetext{
${ }^{1}$ Department of Chemistry, Princeton University, Princeton, NJ

${ }^{2}$ Molecular and Translational Science Division, U.S. Army Medical Research Institute of Infectious Diseases, Frederick, MD

${ }^{3}$ Biotechnology Program, Hagerstown Community College, Hagerstown, MD

${ }^{4}$ Department of Molecular, Cell, and Developmental Biology, University of Colorado, Boulder, CO

${ }^{5}$ Bacteriology Division, U.S. Army Medical Research Institute of Infectious Diseases, Frederick, MD

${ }^{6}$ These authors contributed equally
}

*Correspondence: david.deshazer.civ@mail.mil; mrseyed@princeton.edu 
Bacterial strains, plasmids, and growth conditions. The bacterial strains and plasmids used in this study are described in Table 1. Escherichia coli and B. thailandensis DW503 (hereafter DW503) were grown at $37^{\circ} \mathrm{C}$ on LB agar (Lennox L agar) or in LB broth (Lennox L broth). When appropriate, and unless stated otherwise, antibiotics were added at the following concentrations during genetic procedures: $100 \mu \mathrm{g} / \mathrm{mL}$ ampicillin (Ap), 15 $\mu \mathrm{g} / \mathrm{mL}$ gentamicin $(\mathrm{Gm}), 15 \mu \mathrm{g} / \mathrm{mL}$ tetracycline $(\mathrm{Tc}), 30 \mu \mathrm{g} / \mathrm{mL}$ chloramphenicol $(\mathrm{Cm}), 25$ $\mu \mathrm{g} / \mathrm{mL}$ streptomycin $(\mathrm{Sm})$ and $25 \mu \mathrm{g} / \mathrm{mL}$ kanamycin $(\mathrm{Km})$ for E. coli and $25 \mu \mathrm{g} / \mathrm{mL}$ polymyxin B (Pm), 25/mL $\mu \mathrm{g} \mathrm{Gm}, 25 \mu \mathrm{g} / \mathrm{mL} \mathrm{Tc}, 25 \mu \mathrm{g} / \mathrm{mL} \mathrm{Km}$, and 25/mL $\mu \mathrm{g} \mathrm{Sm}$ for DW503.

DNA manipulation. Restriction enzymes, Antarctic phosphatase, and T4 DNA ligase were purchased from Roche Molecular Biochemicals and were used according to manufacturer's instructions. DNA fragments used in cloning procedures were excised from agarose gels and purified using a PureLink Quick Gel Extraction Kit (Invitrogen). Bacterial genomic DNA was prepared by a previously described protocol. ${ }^{1}$ Plasmids were purified from overnight cultures by using Wizard Plus SV Minipreps (Promega). Plasposons pTnMod-pKmOGm' and pTnMod-OtetRA' (Table S1) were electroporated into E. coli S17-1 using a GenePulser Xcell Electroporation System $(2.5 \mathrm{kV}, 25 \mu \mathrm{F}, 200 \Omega$ and $0.2 \mathrm{~cm}$ gap cuvette).

Transposon mutagenesis of wt $B$. thailandensis DW503 and ORG7. Orangepigmented transposon mutants of wt DW503 were generated using the self-cloning minitransposon TnMod-pKmOGm' (Table S1). Briefly, E. coli S17-1 (pTnMod-pKmOGm') was grown at $37^{\circ} \mathrm{C}$ for $18-20 \mathrm{~h}(250 \mathrm{rpm})$ in LB broth containing Sm and Gm and DW503 was grown in LB broth. One hundred microliters of each saturated culture was added to $3 \mathrm{~mL}$ of sterile $10 \mathrm{mM} \mathrm{MgSO} 4$ in a $3 \mathrm{~mL}$ snap-cap tube, mixed, and filtered through a $0.45 \mu \mathrm{m}$ nitrocellulose filter, using a $25 \mathrm{~mm}$ Swinnex filter apparatus (Millipore). The filters were positioned bacteria-side up onto LB plates supplemented with $100 \mu \mathrm{L}$ of $10 \mathrm{mM} \mathrm{MgSO}_{4}$ and incubated for $8 \mathrm{~h}$ at $37^{\circ} \mathrm{C}$. The filters were then transferred to $50 \mathrm{~mL}$ conical tubes containing $4 \mathrm{~mL}$ of sterile PBS and the bacteria were resuspended with vigorous pipetting and vortexing. One hundred microliter aliquots of the conjugation mixture were spread onto LB plates containing $\mathrm{Gm}$ and $\mathrm{Pm}$ and incubated at $37^{\circ} \mathrm{C}$ for $4-5$ days to identify orange-pigmented colonies.

Non-pigmented transposon mutants of ORG7, also referred to as "white mutants", were obtained as described above using the self-cloning mini-transposon TnMod-OtetRA' (Table S1). E. coli S17-1 (TnMod-OtetRA') was grown in LB broth containing Sm and Tc and ORG7 was grown in LB broth containing Gm. The conjugation mixtures were spread onto LB plates containing Gm, Tc and Pm and incubated at $37^{\circ} \mathrm{C}$ for $4-5$ days to identify non-pigmented white colonies. Pm was used to counterselect E. coli S17-1.

DNA sequencing. Sanger sequencing of plasmid DNA was performed by Beckman Coulter Genomics (Danvers, MA). Oligodeoxyribonucleotide primer TnMod-LT (Table S1) was used to initiate DNA sequence reactions with plasmids obtained from pTnMod-OtetRA' mutants by self-cloning with PstI, XhoI, or NotI. The primers KM-LT and GM-RT were used to initiate DNA sequence reactions with plasmids obtained from pTnMod-pKmOGm' mutants by self-cloning with EcoRI. Custom primers were synthesized at Eurofins Genomics LLC (Louisville, KY). DNA and protein sequences were analyzed with GeneJockeyII and MacVector 7.2 software for the Macintosh computer. The BLASTN program was used to search the non-redundant nucleotide collection database $(\mathrm{nr} / \mathrm{nt})$ with the Basic Local 
Alignment Search Tool (https://blast.ncbi.nlm.nih.gov/Blast.cgi) and B. thailandensis E264 genes and proteins were analyzed using both BLAST and the Integrated Microbial Genomes Database (https://img.jgi.doe.gov/cgi-bin/m/main.cgi).

RNA isolation and gene expression profiling by DNA microarray analysis. TRIzol Reagent (Life Technologies) was employed to isolate total RNA from late logarithmic stage $B$. thailandensis cultures for DNA microarray analysis. DW503 and ORG7 were grown at $37^{\circ} \mathrm{C}$ overnight $(250 \mathrm{rpm})$ in $\mathrm{LB}$ broth and $\mathrm{LB}$ broth containing $\mathrm{Gm}$, respectively. A 100 -fold dilution of saturated culture was used to inoculate $25 \mathrm{~mL}$ of fresh media in a $125 \mathrm{~mL}$ Erlenmeyer flask and the cultures were grown until they reached an OD 600 of 1.0. Twenty $\mathrm{mL}$ of each culture was centrifuged for $15 \mathrm{~min}$ at 5,000 rpm and the pellets were resuspended in $4 \mathrm{~mL}$ TRIzol Reagent and processed for RNA isolation as per the manufacturer's instructions. The $B$. thailandensis DNA microarray was composed of 70mer oligonucleotides representing all annotated genes in the $B$. thailandensis E264 genome. ${ }^{2}$ The oligonucleotides were printed on Corning UltraGAPS aminosilane-coated microscope slides by using a robotic spotter built by Intelligent Automatic Systems (Cambridge, MA) and cross-linked by UV illumination. The RNAs were labelled and hybridized to the DNA microarray using DW503 RNA as the reference. Raw microarray data were generated with TIGR Spotfinder, and then normalized with Lowess, flip-dye analysis and triplicate spot intensity data in MIDAS. ${ }^{3}$ The ORG7 genes with $\log _{2}$ ratios of $\geq 2$ and $\leq-2$ were considered to be significantly differentially regulated.

Differential gene expression using quantitative real-time PCR. RNAprotect Bacterial Reagent and RNeasy Mini Kit (Qiagen) were employed to isolate total RNA from late logarithmic stage $B$. thailandensis cultures for quantitative real-time PCR. DW503 was grown in LB broth, while ORG6 and ORG7 were grown in LB broth containing Gm and incubated at $37^{\circ} \mathrm{C}$ overnight $(250 \mathrm{rpm})$. A 100 -fold dilution of saturated culture was used to inoculate $5 \mathrm{~mL}$ of fresh media in a $50 \mathrm{~mL}$ conical tube and the cultures were grown until they reached an $\mathrm{OD}_{600}$ of 0.6-1.0. Following the manufacturer's instructions with slight modifications, three volumes of RNAprotect (Qiagen) was added to one volume of bacterial

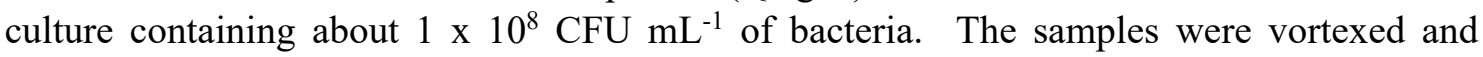
incubated for 5 minutes at room temperature, then centrifuged for 10 minutes at $5000 \mathrm{x} \mathrm{g}$. The supernatant was removed, and the samples were stored in the $-80^{\circ} \mathrm{C}$. B. thailandensis samples were suspended in TE buffer containing lysozyme and Proteinase $\mathrm{K}$ and following the RNeasy Mini Kit (Qiagen) instructions, RNA was purified. RNA samples were treated using a DNA-free ${ }^{\mathrm{TM}}$ Kit (Ambion) to remove DNA contaminants, normalized using the NanoDrop 8000 instrument, and subjected to reverse transcription using iScript ${ }^{\mathrm{TM}}$ Reverse Transcription Supermix for RT-qPCR (BIO-RAD). Quantitative real-time PCR was performed using Power SYBR Green PCR Master Mix (Applied Biosystems) and a QuantStudio $^{\mathrm{TM}}$ 12K Flex Real-Time PCR System (Applied Biosystems). The indicated primers were used for quantification of $\operatorname{org} A$ ( $\operatorname{org} A$-f: 5'-GCTCGCGATTTATGCAACGT-3' and orgA-r: 5'-CTTCCTCGATCGAGAACGCA-3'), BTH_I3310 (BTH_I3310-f: 5'- GCG CGAGTATCTGAAGACGA-3' and BTH_I3310-r: 5'- AGGCACCCGACTTCTTG AAG-3'), BTH_I2534 (BTH_I2534-f: 5'-GAATTCGTGCCCGTGAACTG-3' and BTH_I2534-r: 5'CTGCTCGAAGTAGCCCTTGT-3'), btaQ (btaQ-f: 5'-TCGTCGACGC GTTCTATCTG-3' and btaQ-r: 5'-TCGATCTCGCCGATGAACAG-3'), and 23S rRNA (23S rRNA-f: 5'-AAGT TCCGACCTGCACGAAT-3' and 23S rRNA-r: 5'-GGTTCATGGGGTCTTTCCGT-3') mRNAs. The comparative $\mathrm{CT}(\Delta \Delta \mathrm{CT})$ method was used to determine the fold-change in each 
sample compared to the reference sample DW503, with the endogenous control of 23S rRNA. The cDNA samples from three independent biological replicates were each measured in triplicate. The ORG7 or ORG6 genes with $\log _{2}$ fold change of $\geq 1$ and $\leq-1$ were considered to be significantly differentially regulated.

Whole cell proteomic analysis. Three biological replicates of DW503 and ORG7 were grown at $37^{\circ} \mathrm{C} / 250 \mathrm{rpm}$ overnight in LB broth and LB broth with $\mathrm{Gm}(10 \mu \mathrm{g} / \mathrm{mL})$, respectively. The saturated cultures were diluted 100 -fold into $50 \mathrm{~mL}$ of LB broth in a 250 $\mathrm{mL}$ Erlenmeyer flask, and grown at $37^{\circ} \mathrm{C} / 250 \mathrm{rpm}$. One $\mathrm{mL}$ of each culture was sampled at late logarithmic growth by collecting the cells via centrifugation $\left(4500 \mathrm{~g}, 30 \mathrm{~min}, 4^{\circ} \mathrm{C}\right)$, removing media, and storing the cell pellets at $-80^{\circ} \mathrm{C}$. The cell pellets were suspended in 100 $\mu \mathrm{L}$ lysis buffer (5\% (w/v) SDS, $10 \mathrm{mM}$ tris(2-carboxyethyl)phosphine hydrochloride (TCEP), $40 \mathrm{mM}$ chloroacetamide, $50 \mathrm{mM}$ Tris, $\mathrm{pH} \mathrm{8.5)}$ and lysed using a Bioruptor Pico (Diagenode) with two rounds of 10 cycles ( 30 seconds on, 30 seconds off) at $25^{\circ} \mathrm{C}$, boiling lysates for 10 minutes in between. SDS lysates were cleared by centrifugation $\left(21,130 \mathrm{~g}, 30 \mathrm{~min}, 25^{\circ} \mathrm{C}\right)$. Protein concentrations were determined using the tryptophan fluorescence assay. ${ }^{4}$

SDS lysates were processed using the SP3 methods. ${ }^{5}$ Briefly, carboxylatefunctionalized speedbeads (GE Life Sciences) were added to the lysates, and protein was precipitated onto the beads with the addition of $80 \%(\mathrm{v} / \mathrm{v})$ acetonitrile. The beads were washed twice with $80 \%(\mathrm{v} / \mathrm{v})$ ethanol and twice with acetonitrile. Proteins were digested with the addition of 1:100 lysyl endoproteinase (LysC, Wako) in $50 \mathrm{mM}$ Tris $\mathrm{pH} 8.5$ at $37^{\circ} \mathrm{C}$ for 4 hours in a thermomixer shaking at $600 \mathrm{rpm}$, then the addition of 1:100 trypsin (Pierce) at $37^{\circ} \mathrm{C}$ overnight shaking at $600 \mathrm{rpm}$. Peptides were cleaned up in the same tubes using the speedbeads by adding $95 \%(\mathrm{v} / \mathrm{v})$ acetonitrile to precipitate tryptic peptides, then washed once with acetonitrile. Tryptic peptides were recovered in $1 \%(\mathrm{v} / \mathrm{v})$ trifluoroacetic acid (TFA) and $3 \%(\mathrm{v} / \mathrm{v})$ acetonitrile. Tryptic peptide yields were determined by scanning absorbance at 280 nm using a NanoDrop 2000 (Thermo Scientific).

To improve proteome coverage, the three biological replicates for DW503 were pooled and three biological replicates for ORG7 were pooled and each was fractionated into 6 concatenated fractions using a high $\mathrm{pH}$ reversed-phase $\mathrm{C} 18$ column with $10 \mathrm{mM}$ ammonium formate $\mathrm{pH} 10$ (buffer A) and buffer A with $80 \%(\mathrm{v} / \mathrm{v}$ ) acetonitrile (buffer B). The custom fabricated $\mathrm{C} 18$ column $(0.5 \mathrm{~mm}$ x $200 \mathrm{~mm}, 1.8 \mu \mathrm{m}, 120 \AA$ Uchrom, nanoLCMS Solutions) was maintained at $25^{\circ} \mathrm{C}$ running $15 \mu \mathrm{L} /$ minute using a Waters M-class UPLC. Peptides were gradient-separated from $3-50 \%$ B in $25 \mathrm{~min}$, then from $50-100 \%$ B in 5 min. Fractions were collected for $30 \mathrm{~s}$ and concatenated 7 times throughout the gradient elution, dried using a speedvac (Thermo Scientific), and stored at $-80^{\circ} \mathrm{C}$. High $\mathrm{pH} \mathrm{C} 18$ fractions were suspended in 3\% (v/v) acetonitrile, $0.1 \%(\mathrm{v} / \mathrm{v})$ TFA.

For all LC-MS/MS analyses, $1 \mu \mathrm{g}$ tryptic peptides were loaded onto a $25 \mathrm{~cm} \times 75 \mu \mathrm{m}$ inner diameter, $1.7 \mu \mathrm{m}, 130 \AA$ M-class $\mathrm{C} 18$ column (Waters) maintained at $50^{\circ} \mathrm{C}$. A Waters M-class UPLC was interfaced with an Orbitrap Fusion mass spectrometer (Thermo Scientific) using a NanoSpray flex source. All peptide samples were separated at $300 \mathrm{~nL} / \mathrm{min}$ with mobiles phases containing $0.1 \%(\mathrm{v} / \mathrm{v})$ formic acid, buffer $\mathrm{A}$ in water only and buffer B in acetonitrile only using a gradient of $3-5 \% \mathrm{~B}$ in $5 \mathrm{~min}$, then $5-25 \% \mathrm{~B}$ in $100 \mathrm{~min}$, then $25-$ $32 \% \mathrm{~B}$ in $20 \mathrm{~min}$, then $32-85 \% \mathrm{~B}$ in $1 \mathrm{~min}$, and holding $85 \% \mathrm{~B}$ for $4 \mathrm{~min}$. Eluting peptide ions were scanned from $380-1500 \mathrm{~m} / \mathrm{z}$ at a resolution of 120,000 with an AGC target of $2 \mathrm{E} 5$ ions and a maximum injection time of $50 \mathrm{~ms}$. Data-dependent acquisition was set for Top Speed with a 3 s cycle, 1.6 Da isolation window using the quadrupole, higher energy 
collision dissociation (HCD) with 35\% collision energy, scanning in the linear ion trap, with a AGC target of 1E4 and a $35 \mathrm{~ms}$ maximum injection time. Dynamic exclusion was enabled for 20 seconds $+/-10 \mathrm{ppm}$.

Raw MS datafiles were processed with MaxQuant (version 1.6.3.4) for protein identifications using the Burkholderia thailandensis Uniprot database, Proteome ID UP000001930, last modified October 26, 2018. Cysteine carbamidomethylation was set as a fixed modification while methionine oxidation and protein $\mathrm{N}$-terminal acetylation were set as variable modifications. All peptides and proteins were thresholded at a $1 \%$ false discovery rate (FDR) using matching between runs (MBR) with High $\mathrm{pH} \mathrm{C18}$ fractions, six fractions for DW503 and six fractions for ORG7. All data was Cyclic Loess normalized between groups (DW503 and ORG7) prior to statistical analyses. Differential protein abundance was calculated using Limma (Bioconductor.org) to generate a linear model for fold-change estimation and standard error then an Empirical Bayes implementation of an independent $t$ test where the null distribution is inferred from the global data, and treatment distribution is Bayesian updated. FDR (q-values) were then generated using the Benjamini-Hochberg limma implementation.

Routine HPLC-MS and NMR analysis for detection of thailandenes. Low resolution HPLC-MS analysis was performed on a 1260 Infinity Series HPLC system (Agilent) equipped with an automated liquid sampler, a diode array detector, and a 6120 Series ESI mass spectrometer using an analytical Luna C18 column (Phenomenex, $5 \mu \mathrm{m}, 4.6$ x $100 \mathrm{~mm}$ ) operating at $0.5 \mathrm{~mL} / \mathrm{min}$ with a gradient of $10 \% \mathrm{MeCN}$ in $\mathrm{H}_{2} \mathrm{O}$ to $100 \% \mathrm{MeCN}$ over $30 \mathrm{~min}$. Both $\mathrm{MeCN}$ and $\mathrm{H}_{2} \mathrm{O}$ contained $0.1 \%$ (v/v) formic acid. High-resolution (HR) HPLC-MS analysis was carried out on a 6540 UHD Accurate Mass Q-tof LC-MS system (Agilent), consisting of a 1260 Infinity Series HPLC system, an automated liquid sampler, a diode array detector, a JetStream ESI source, and the 6540 Series Q-tof. HPLC purifications were carried out on an Agilent 1260 Infinity Series analytical or preparative HPLC system equipped with a photodiode array detector and an automated fraction collector. NMR spectra were collected at the Princeton Chemistry NMR Core Facility in a Bruker Avance III 500 $\mathrm{MHz}$ spectrometer equipped with a ${ }^{1} \mathrm{H}$-optimized cryoprobe.

Thailandene product screening. Frozen stocks of DW503 were streaked out onto LB-agar plates. Likewise, the ORG and WM strains indicated in Fig. 6 were streaked onto selective $\mathrm{Gm} / \mathrm{LB}$-agar plates $(15 \mu \mathrm{g} / \mathrm{mL} \mathrm{Gm})$. The strains were incubated at $37^{\circ} \mathrm{C}$ overnight. A single colony was used to inoculate liquid LB medium (D503) or LB medium containing $\mathrm{Gm}\left(15 \mu \mathrm{g} / \mathrm{mL}, \mathrm{ORG}\right.$ and WM strains) and incubated at $30{ }^{\circ} \mathrm{C} / 250 \mathrm{rpm}$ overnight. $20 \mathrm{~mL}$ of LB-Mops medium (LB containing $50 \mathrm{mM}$ Mops, $\mathrm{pH}$ 7.0) in a $50 \mathrm{~mL}$ Erlenmeyer flask was inoculated with each of overnight cultures to an initial $\mathrm{OD}_{600}$ of 0.05 . The cultures were grown for $36 \mathrm{~h}$ at $30{ }^{\circ} \mathrm{C} / 200 \mathrm{rpm}$. Then $5 \mathrm{~mL}$ of each culture was transferred into $15 \mathrm{~mL}$ Falcon tube and extracted with $10 \mathrm{~mL}$ of ethyl acetate. The organic layer was dried in vacuo, dissolved in $300 \mu \mathrm{L} \mathrm{MeOH} ; 10 \mu \mathrm{L}$ were analyzed by HPLC-MS as described above.

Optimizing production of thailandenes. Upon identification of the thailandene peaks, thailandene production was optimized by screening ORG6 growth in five different media: LB, LB-Mops, YPG (per L: 1 g yeast extract, $0.2 \%(\mathrm{v} / \mathrm{v})$ glycerol, and $2 \mathrm{~g}$ peptone), TSBY (per L: $3 \mathrm{~g}$ trypticase soy broth and $0.5 \mathrm{~g}$ yeast extract), and BC (per L: $1 \mathrm{~g} / \mathrm{L}$ casein, 1 $\mathrm{g} / \mathrm{L}$ lactose, $1 \mathrm{~g} / \mathrm{L}$ sucrose, $0.5 \mathrm{~g} / \mathrm{L} \mathrm{NaCl}$ and $150 \mathrm{mg} / \mathrm{L}$ yeast extract).

Fifty mL Erlenmeyer flasks containing $20 \mathrm{~mL}$ of LB, LB-Mops, YPG, TSBY and BC media were prepared exactly as described above. ORG6 was inoucated to an initial OD600 of 
0.05 in each medium and incubated at $30{ }^{\circ} \mathrm{C} / 200 \mathrm{rpm}$. Thailandene production was assessed by HPLC-MS as described above at $24 \mathrm{~h}, 36 \mathrm{~h}$ and $48 \mathrm{~h}$ for each of the five conditions in duplciates. $\mathrm{BC}$ medium at $48 \mathrm{~h}$ gave the highest production of thailandenes; it was used in large-scale thailandene production cultures

Large-scale cultivation and isolation. ORG6 was streaked out onto LB agar plates containing Gm $(15 \mu \mathrm{g} / \mathrm{mL})$ and incubated at $37{ }^{\circ} \mathrm{C}$ overnight. Single colonies were used to inoculate $5 \mathrm{~mL}$ of LB containing $\mathrm{Gm}(15 \mu \mathrm{g} / \mathrm{mL})$. After overnight incubation at $30{ }^{\circ} \mathrm{C} / 250$ rpm overnight, $2.5 \mathrm{~mL}$ were used to inoculated in $250 \mathrm{~mL}$ of $\mathrm{LB} / \mathrm{Gm}(15 \mu \mathrm{g} / \mathrm{mL})$ in a $1 \mathrm{~L}$ Erlenmeyer flask. The cultures were grown overnight at $30^{\circ} \mathrm{C} / 250 \mathrm{rpm}$ overnight. Then $20 \mathrm{x}$ $1 \mathrm{~L} \mathrm{BC}$ media (in $3.8 \mathrm{~L}$ Fernbach flasks) were inoculated with ORG6 to an initial OD 600 of 0.05 and incubated at $30{ }^{\circ} \mathrm{C} / 250 \mathrm{rpm}$ for 48 hours. The cultures were transferred, $1 \mathrm{~L}$ at a time, to a $3 \mathrm{~L}$ separatory funnel and extracted with $1.5 \mathrm{~L}$ of ethyl acetate. The combined, orange-colored organic layer was completely dried in vacuo and dry-load onto a pre-packed C18-functionalized silica gel column (Phenomenex, $10 \mathrm{~g}$ ). Elution was carried out with 150 $\mathrm{mL}$ each of $20 \%, 40 \%, 60 \%, 80 \%$, and $100 \% \mathrm{MeOH}$ in water. Thailandene A-C were detected in the $100 \%$ fractions. This fraction was then subjected to reversed-phase HPLC using an Agilent Eclipse XD8 C8 column $(9.4$ x $250 \mathrm{~mm}, 5 \mu \mathrm{m})$, operating at flow rate 2 $\mathrm{mL} / \mathrm{min}$ and a gradient $70-100 \%$ aqueous acetonitrile over $30 \mathrm{~min}$. Under these purification conditions, (10-12) eluted at 11, 25, $22 \mathrm{~min}$, respectively. This allowed isolation of Thailandenes 10 (1.6 mg), $11(1.0 \mathrm{mg})$ and $12(1.3 \mathrm{mg})$.

Structure elucidation. The structures of compounds 10-12 were determined by analysis of HR-MS data as well as ${ }^{1} \mathrm{H}$ and 2D (gCOSY, TOCSY, HSQC and HMBC) NMR spectra. The molecular formula and HR-ESI-MS data are listed in Table S4

Mosher's reaction. The absolute configuration of the stereogenic centers at C-12 bearing a secondary alcohol, was determined using the modified Mosher's method. (R)- and (S)- $\alpha$-methoxy- $\alpha$-(trifluoromethyl) phenylacetyl chloride (MTPA-Cl) were obtained from Sigma-Alrich and used for esterification of the hydroxy group C-12 to $S$ - and $R$-MTPA esters, respectively, according to published procedures. ${ }^{6}$ The calculation of the $\Delta \delta S-R$ values of $S$ and $R$-MTPA esters based on the analysis of their ${ }^{1} \mathrm{H}$ and COSY NMR spectra established the absolute configuration of $12 R$ (Fig. S7).

Bioactivity assays. Antibiotic activity assays were determined according to the 2003 guidelines of the Clinical and Laboratory Standards Institute (CLSI, formerly NCCLS) using the microtiter method. The data were fit to a dose-response curve to determine half-maximal inhibitory $\left(\mathrm{IC}_{50}\right)$ or half-maximal elicitor $\left(\mathrm{EC}_{50}\right.$, for E. coli) concentrations (Table 1). 
Table S1. Strains, plasmids, and primers utilized in this study.

\begin{tabular}{|c|c|c|}
\hline $\begin{array}{c}\text { Strains, plasmids and } \\
\text { primers }\end{array}$ & Description & $\begin{array}{l}\text { Reference } \\
\text { or source }\end{array}$ \\
\hline \multicolumn{3}{|l|}{ E. coli } \\
\hline S17-1 & $\begin{array}{l}\text { Mobilizing strain (expresses RP4 tra genes); } \mathrm{Sm}^{\mathrm{r}} \mathrm{Gm}^{\mathrm{s}} \\
\mathrm{Pm}^{\mathrm{s}} \mathrm{Tc}^{\mathrm{s}}\end{array}$ & 7 \\
\hline XL1-Blue MRF' Kan & High-efficiency transformation strain; $\mathrm{Km}^{\mathrm{r}} \mathrm{Gm}^{\mathrm{s}} \mathrm{Tc}^{\mathrm{s}}$ & Stratagene \\
\hline XL10-Gold Kan ${ }^{r}$ & High-efficiency transformation strain; $\mathrm{Km}^{\mathrm{r}} \mathrm{Tc}^{\mathrm{r}} \mathrm{Gm}^{\mathrm{s}}$ & Stratagene \\
\hline SoloPack Gold & High-efficiency transformation strain; $\mathrm{Cm}^{\mathrm{r}} \mathrm{Tc}^{\mathrm{r}} \mathrm{Gm}^{\mathrm{s}}$ & Stratagene \\
\hline \multicolumn{3}{|l|}{ B. thailandensis } \\
\hline E264 & $\begin{array}{l}\text { Type strain isolated from a rice field soil sample in } \\
\text { central Thailand; } \mathrm{Km}^{\mathrm{r}} \mathrm{Gm}^{\mathrm{r}} \mathrm{Pm}^{\mathrm{r}} \mathrm{Tc}^{\mathrm{s}}\end{array}$ & 8 \\
\hline DW503 & E264 derivative; $\Delta($ amr $A B$-opr $A) ; \mathrm{Km}^{\mathrm{s}} \mathrm{Gm}^{\mathrm{s}} \mathrm{Pm}^{\mathrm{r}} \mathrm{Tc}^{\mathrm{s}}$ & 9 \\
\hline ORG1 & $\begin{array}{l}\text { DW503 derivative; } \mathrm{Tn} M o d-\mathrm{pKmOGm} \text { ' insertion } \\
\text { upstream of } \operatorname{org} A ; \mathrm{Km}^{\mathrm{s}} \mathrm{Gm}^{\mathrm{r}}\end{array}$ & This study \\
\hline ORG2 & $\begin{array}{l}\text { DW503 derivative; TnMod-pKmOGm' insertion } \\
\text { upstream of } \operatorname{org} A ; \mathrm{Km}^{\mathrm{s}} \mathrm{Gm}^{\mathrm{r}}\end{array}$ & This study \\
\hline ORG5 & DW503 derivative; $\operatorname{org} A:: \mathrm{Tn} M o d-\mathrm{pKmOGm} ; \mathrm{Km}^{\mathrm{s}} \mathrm{Gm}^{\mathrm{r}}$ & This study \\
\hline ORG6 & $\begin{array}{l}\text { DW503 derivative; BTH_I2539::TnMod-pKmOGm'; } \\
\mathrm{Km}^{\mathrm{s}} \mathrm{Gm}^{\mathrm{r}}\end{array}$ & This study \\
\hline ORG7 & $\begin{array}{l}\text { DW503 derivative; } \mathrm{Tn} M o d-\mathrm{pKmOGm} \text { ' insertion } \\
\text { upstream of } \operatorname{org} A ; \mathrm{Km}^{\mathrm{s}} \mathrm{Gm}^{\mathrm{r}}\end{array}$ & This study \\
\hline WM1 & ORG7 derivative; $\operatorname{org} C:: \operatorname{Tn} M o d-\mathrm{O}$ tetR $A^{\prime} ; \mathrm{Gm}^{\mathrm{r}} \mathrm{Tc}^{\mathrm{r}}$ & This study \\
\hline WM3 & ORG7 derivative; $\operatorname{org} C:: \operatorname{Tn} M o d-\mathrm{O}$ tetR $A^{\prime} ; \mathrm{Gm}^{\mathrm{r}} \mathrm{Tc}^{\mathrm{r}}$ & This study \\
\hline WM6 & ORG7 derivative; $\operatorname{org} C:: \operatorname{Tn} M o d-O$ tetR $A^{\prime} ; \mathrm{Gm}^{\mathrm{r}} \mathrm{Tc}^{\mathrm{r}}$ & This study \\
\hline WM7 & ORG7 derivative; $\operatorname{org} B:: \operatorname{Tn} M o d-O$ tetR $A^{\prime} ; \mathrm{Gm}^{\mathrm{r}} \mathrm{Tc}^{\mathrm{r}}$ & This study \\
\hline WM8 & ORG7 derivative; $\operatorname{org} B:: \operatorname{Tn} M o d-\mathrm{O}$ tetR $A^{\prime} ; \mathrm{Gm}^{\mathrm{r}} \mathrm{Tc}^{\mathrm{r}}$ & This study \\
\hline WM9 & ORG7 derivative; $\operatorname{org} A:: \operatorname{Tn} M o d-\mathrm{O}$ tetR $A^{\prime} ; \mathrm{Gm}^{\mathrm{r}} \mathrm{Tc}^{\mathrm{r}}$ & This study \\
\hline WM10 & ORG7 derivative; $\operatorname{org} C:: \operatorname{Tn} M o d-\mathrm{O} t e t R A^{\prime} ; \mathrm{Gm}^{\mathrm{r}} \mathrm{Tc}^{\mathrm{r}}$ & This study \\
\hline WM11 & ORG7 derivative; $\operatorname{org} B:: \operatorname{Tn} M o d-\mathrm{O}$ tetR $A^{\prime} ; \mathrm{Gm}^{\mathrm{r}} \mathrm{Tc}^{\mathrm{r}}$ & This study \\
\hline WM12 & ORG7 derivative; $\operatorname{org} C:: \operatorname{Tn} M o d-\mathrm{O}$ tetR $A^{\prime} ; \mathrm{Gm}^{\mathrm{r}} \mathrm{Tc}^{\mathrm{r}}$ & This study \\
\hline WM13 & ORG7 derivative; $\operatorname{org} A:: \operatorname{Tn} M o d-\mathrm{O}$ tetR $A^{\prime} ; \mathrm{Gm}^{\mathrm{r}} \mathrm{Tc}^{\mathrm{r}}$ & This study \\
\hline WM14 & ORG7 derivative; $\operatorname{org} C:: \mathrm{Tn} M o d-\mathrm{O}$ tet $R A^{\prime} ; \mathrm{Gm}^{\mathrm{r}} \mathrm{Tc}^{\mathrm{r}}$ & This study \\
\hline
\end{tabular}




\begin{tabular}{|c|c|c|}
\hline WM15 & ORG7 derivative; $\operatorname{org} A:: \operatorname{Tn} M o d-\mathrm{O}$ tetR $A^{\prime} ; \mathrm{Gm}^{\mathrm{r}} \mathrm{Tc}^{\mathrm{r}}$ & This study \\
\hline \multicolumn{3}{|l|}{ Plasmids } \\
\hline pTnMod-pKmOGm' & $\begin{array}{l}\text { Plasposon harboring a self-cloning mini-transposon with } \\
\text { a promoterless } \mathrm{Km}^{\mathrm{r}} \text { gene that can form transcriptional } \\
\text { fusions when integrated downstream of an active } \\
\text { promoter; pMB1 oriR; } \mathrm{Gm}^{\mathrm{r}}\end{array}$ & $\begin{array}{c}\text { Jonathan J. } \\
\text { Dennis }\end{array}$ \\
\hline RP4 & Broad-host-range plasmid; $\mathrm{Ap}^{\mathrm{r}} \mathrm{Km}^{\mathrm{r}} \mathrm{Tc}^{\mathrm{r}}$ & 10 \\
\hline pCR2.1-TOPO & $3.9 \mathrm{~kb}$ TA cloning vector; $\mathrm{Km}^{\mathrm{r}} \mathrm{Ap}^{\mathrm{r}}$ & Invitrogen \\
\hline pDD806 & $\begin{array}{l}\text { pCR2.1-TOPO containing PCR product generated with } \\
\text { RP4 and the Tet-up/Tet-dn primer pair; } \mathrm{Km}^{\mathrm{r}} \mathrm{Ap}^{\mathrm{r}} \mathrm{Tc}^{\mathrm{r}}\end{array}$ & This study \\
\hline pTnMod-OGm' & $\begin{array}{l}\text { Plasposon harboring a self-cloning mini-transposon; } \\
\text { pMB1 oriR; } \mathrm{Gm}^{\mathrm{r}}\end{array}$ & 11 \\
\hline $\mathrm{pTnMod-OtetRA^{ \prime }}$ & $\begin{array}{l}\text { pTnMod-OGm' digested with } C l a \mathrm{I} \text { and SpeI and } \\
\text { containing SpeI-XbaI insert from pDD806; Tc }{ }^{\mathrm{r}}\end{array}$ & This study \\
\hline \multicolumn{3}{|l|}{ Primers } \\
\hline Tet-up & 5'-TCAATCGTCACCCTTTCTCG-3' & This study \\
\hline Tet-dn & 5'-AAGTCGCCTTGACCCGCATG-3' & This study \\
\hline KM-LT & 5'-CGTTTCCCGTTGAATATGGC-3' & This study \\
\hline GM-RT & 5'-GCCGCGGCCAATTCGAGCTC-3' & This study \\
\hline TnMod-LT & 5'-CCTGGTACCGTCGACATGCA-3' & This study \\
\hline
\end{tabular}


Table S2. Genes associated with the $B$. thailandensis orange-pigment phenotype and the predicted functions of the encoded proteins.

\begin{tabular}{|c|c|c|}
\hline Gene/Locus tag & bp/amino acids & Product description \\
\hline $\operatorname{orgA/BTH\_ II2349}$ & $1617 \mathrm{bp} / 538$ aа & Acyl transferase domain protein \\
\hline $\operatorname{org} B / \mathrm{BTH}$ _II2348 & $6414 \mathrm{bp} / 2137$ aa & Polyketide synthase \\
\hline orgC/BTH_II2347 & $4143 \mathrm{bp} / 1380$ aa & Cytochrome P450-related protein \\
\hline orgD/BTH_II2346 & $1449 \mathrm{bp} / 482$ aa & $\begin{array}{l}\text { Monooxygenase, flavin-binding } \\
\text { family }\end{array}$ \\
\hline orgE/BTH_II2345 & $702 \mathrm{bp} / 233$ aa & $\begin{array}{l}\text { ABC transporter, ATP-binding } \\
\text { protein }\end{array}$ \\
\hline orgF/BTH_II2344 & $1434 \mathrm{bp} / 477$ aa & $\mathrm{ABC}$ transporter, permease protein \\
\hline orgG/BTH_II2343 & $783 \mathrm{bp} / 260$ aa & $\begin{array}{l}\text { Outer membrane lipoprotein-sorting } \\
\text { protein }\end{array}$ \\
\hline orgH/BTH_II2342 & $1299 \mathrm{bp} / 432$ aa & Hypothetical protein \\
\hline orgI/BTH_II2341 & $399 \mathrm{bp} / 132$ aa & $\begin{array}{l}\text { Protein of unknown function } \\
\text { DUF4345 }\end{array}$ \\
\hline orgJ/BTH_II2340 & $666 \mathrm{bp} / 221$ aa & $\begin{array}{l}\text { 4'-phosphopantetheinyl transferase } \\
\text { family protein }\end{array}$ \\
\hline orgK/BTH_II2339 & $1104 \mathrm{bp} / 367$ aa & $\begin{array}{l}\text { Triacylglycerol esterase/lipase EstA, } \\
\text { alpha/beta hydrolase fold protein }\end{array}$ \\
\hline orgL/BTH_II2338 & $2403 \mathrm{bp} / 800$ aa & $\begin{array}{l}\text { Diguanylate } \\
\text { cyclase/phosphodiesterase }\end{array}$ \\
\hline orgM/BTH_II2337 & $741 \mathrm{bp} / 246$ aa & $\begin{array}{l}\text { Haem oxygenase-like, multi-helical } \\
\text { protein }\end{array}$ \\
\hline
\end{tabular}


Table S3. Gene expression profiling by DNA microarray technology.

\begin{tabular}{|c|c|c|}
\hline Locus tag/gene & Product & $\begin{array}{l}\text { Change } \\
\left(\log _{2} \text { fold) }\right.\end{array}$ \\
\hline BTH_I0088 & RNA polymerase sigma factor RpoD $(\sigma 70)$ & 2.5 \\
\hline BTH_I0164 & $\begin{array}{l}\text { Heat shock protein HslVU, ATPase subunit HslU } \\
(\mathrm{ClpY})\end{array}$ & 2.2 \\
\hline BTH_I0359 & Protein of unknown function DUF3567 & 2.1 \\
\hline BTH_I1308 & Chaperone protein DnaK & 2.4 \\
\hline BTH_I2716 & LysR family transcriptional regulator & -2.6 \\
\hline BTH_I2809 & Heat shock protein, Hsp20 family & 3.4 \\
\hline BTH_I2810 & Heat shock protein, Hsp20 family & 2.4 \\
\hline BTH_IIO200 & Major facilitator family transporter & 2.2 \\
\hline BTH_IIO201 & Gycerate kinase & 2.6 \\
\hline BTH_IIO203 & Carbohydrate diacid regulator & 2.1 \\
\hline BTH_IIO764 & Conserved hypothetical protein & -2.6 \\
\hline BTH_IIO907 & 1-phosphofructokinase & 2.1 \\
\hline btaN & $\begin{array}{l}\text { Cluster } 12 \text { secondary metabolite biosynthesis } \\
\text { (bactobolin) }\end{array}$ & -2.3 \\
\hline$b t a O$ & $\begin{array}{l}\text { Cluster } 12 \text { secondary metabolite biosynthesis } \\
\text { (bactobolin) }\end{array}$ & -2.3 \\
\hline btaP & $\begin{array}{l}\text { Cluster } 12 \text { secondary metabolite biosynthesis } \\
\text { (bactobolin) }\end{array}$ & -2.5 \\
\hline$b t a Q$ & $\begin{array}{l}\text { Cluster } 12 \text { secondary metabolite biosynthesis } \\
\text { (bactobolin) }\end{array}$ & -2.6 \\
\hline btaS & $\begin{array}{l}\text { Cluster } 12 \text { secondary metabolite biosynthesis } \\
\text { (bactobolin) }\end{array}$ & -2.5 \\
\hline$b t a T$ & $\begin{array}{l}\text { Cluster } 12 \text { secondary metabolite biosynthesis } \\
\text { (bactobolin) }\end{array}$ & -2.4 \\
\hline BTH_III307 & Methyltransferase domain protein & -2.2 \\
\hline BTH_III889 & Protein of unknown function DUF4150 & -2.0 \\
\hline BTH_III925 & Chitin binding domain protein & -2.4 \\
\hline$h m q G$ & $\begin{array}{l}\text { Cluster } 9 \text { secondary metabolite biosynthesis (4- } \\
\text { hydroxy-3-methyl-2-alkylquinoline) }\end{array}$ & -2.9 \\
\hline
\end{tabular}




\begin{tabular}{|c|c|c|}
\hline$h m q E$ & $\begin{array}{l}\text { Cluster } 9 \text { secondary metabolite biosynthesis (4- } \\
\text { hydroxy-3-methyl-2-alkylquinoline) }\end{array}$ & -2.3 \\
\hline$h m q D$ & $\begin{array}{l}\text { Cluster } 9 \text { secondary metabolite biosynthesis (4- } \\
\text { hydroxy-3-methyl-2-alkylquinoline) }\end{array}$ & -2.5 \\
\hline$h m q B$ & $\begin{array}{l}\text { Cluster } 9 \text { secondary metabolite biosynthesis (4- } \\
\text { hydroxy-3-methyl-2-alkylquinoline) }\end{array}$ & -2.4 \\
\hline BTH_II1972 & Hypothetical protein & -3.6 \\
\hline BTH_II1997 & Hypothetical protein & 2.3 \\
\hline malB & $\begin{array}{l}\text { Cluster } 8 \text { secondary metabolite biosynthesis } \\
\text { (malleilactone) }\end{array}$ & -2.6 \\
\hline BTH_II2252 & Carbon starvation protein $\mathrm{A}$ & 4.9 \\
\hline $\operatorname{org} M$ & Cluster 5 secondary metabolite biosynthesis & 2.9 \\
\hline $\operatorname{org} L$ & Cluster 5 secondary metabolite biosynthesis & 2.1 \\
\hline $\operatorname{org} K$ & Cluster 5 secondary metabolite biosynthesis & 4.2 \\
\hline $\operatorname{org} J$ & Cluster 5 secondary metabolite biosynthesis & 2.5 \\
\hline $\operatorname{org} I$ & Cluster 5 secondary metabolite biosynthesis & 3.7 \\
\hline orgH & Cluster 5 secondary metabolite biosynthesis & 3.3 \\
\hline $\operatorname{org} G$ & Cluster 5 secondary metabolite biosynthesis & 4.3 \\
\hline $\operatorname{org} F$ & Cluster 5 secondary metabolite biosynthesis & 3.8 \\
\hline $\operatorname{org} E$ & Cluster 5 secondary metabolite biosynthesis & 4.2 \\
\hline $\operatorname{org} D$ & Cluster 5 secondary metabolite biosynthesis & 4.5 \\
\hline $\operatorname{org} B$ & Cluster 5 secondary metabolite biosynthesis & 4.6 \\
\hline $\operatorname{org} A$ & Cluster 5 secondary metabolite biosynthesis & 5.0 \\
\hline
\end{tabular}

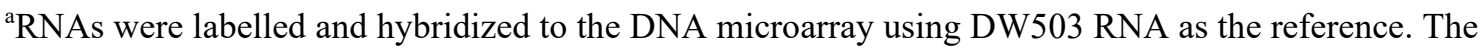
41 ORG7 genes with $\log _{2}$ ratios of $\geq 2$ and $\leq-2$ were considered to be significantly up- and downregulated, respectively. 
Table S4. Observed and calculated HR-MS data for compounds 10-12.

\begin{tabular}{cccc}
\hline & {$[\mathbf{M}+\mathbf{N a}]^{+}{ }_{\text {calc }}$} & {$[\mathbf{M}+\mathbf{N a}]^{+}{ }^{+}{ }$} & $\Delta \mathbf{p p m}$ \\
\hline Thailandene A (10) & 267.1356 & 267.1357 & 0.37 \\
Thailandene B (11) & 263.1406 & 263.1407 & 0.38 \\
Thailandene C (12) & 267.1356 & 267.1354 & 0.75 \\
\hline
\end{tabular}


Table S5. NMR assignments of 10, 11 and 12 in acetone- $d_{6}$. The structure and number scheme for the compounds are shown below the table.

\begin{tabular}{|c|c|c|c|c|c|c|}
\hline & \multicolumn{2}{|r|}{10} & \multicolumn{2}{|r|}{11} & \multicolumn{2}{|r|}{12} \\
\hline No. & $\delta_{C^{a}}$, type & $\begin{array}{l}\delta_{\mathrm{H}}^{\mathrm{b}} \text { mult }(J \text { in } \\
\mathrm{Hz})\end{array}$ & $\delta_{\mathrm{C}}{ }^{\mathrm{a}}$, type & $\begin{array}{l}\delta_{\mathrm{H}^{\mathrm{b}}} \text { mult }\left(\begin{array}{ll}J & \text { in } \\
\mathrm{Hz}\end{array}\right)\end{array}$ & $\delta_{\mathrm{C}}^{\mathrm{a}}$, type & $\begin{array}{l}\delta_{\mathrm{H}^{\mathrm{b}}} \text { mult }\left(\begin{array}{ll}J & \text { in } \\
\mathrm{Hz}\end{array}\right)\end{array}$ \\
\hline 1 & $193.5, \mathrm{C}$ & $9.57, \mathrm{~d}(8.0)$ & 193.6, C & $9.56, \mathrm{~d}(8.0)$ & $169.4, \mathrm{C}$ & \\
\hline 2 & $\begin{array}{l}\text { 131.6, } \\
\mathrm{CH}\end{array}$ & $\begin{array}{l}6.14 \text {, dd (15.0, } \\
8.0)\end{array}$ & $\begin{array}{l}131.8 \\
\mathrm{CH}\end{array}$ & $\begin{array}{l}6.14 \text {, dd }(15.0 \text {, } \\
8.0)\end{array}$ & $\begin{array}{l}120.2 \\
\mathrm{CH}\end{array}$ & $6.61, \mathrm{~d}(15.0)$ \\
\hline 3 & $\begin{array}{l}152.3 \\
\mathrm{CH}\end{array}$ & $\begin{array}{l}7.34, \mathrm{dd}(15.0, \\
11.0)\end{array}$ & $\begin{array}{l}152.5 \\
\mathrm{CH}\end{array}$ & $7.34, \mathrm{~m}$ & $\begin{array}{l}145.0 \\
\mathrm{CH}\end{array}$ & $\begin{array}{l}8.06 \text {, dd (15.0, } \\
11.5)\end{array}$ \\
\hline 4 & $\begin{array}{l}131.0 \\
\mathrm{CH}\end{array}$ & $\begin{array}{l}6.61, \mathrm{dd} \text { (15.0, } \\
11.0)\end{array}$ & $\begin{array}{l}131.0 \\
\mathrm{CH}\end{array}$ & $\begin{array}{l}6.60, \mathrm{dd} \text { (15.0, } \\
11.0)\end{array}$ & $\begin{array}{l}129.4 \\
\mathrm{CH}\end{array}$ & $7.14, \mathrm{~m}$ \\
\hline 5 & $\begin{array}{l}143.2 \\
\mathrm{CH}\end{array}$ & $\begin{array}{l}6.90, \mathrm{dd} \quad(15.0, \\
11.0)\end{array}$ & $\begin{array}{l}143.4 \\
\mathrm{CH}\end{array}$ & $\begin{array}{l}6.89, \mathrm{dd} \quad(15.0, \\
11.0)\end{array}$ & $\begin{array}{l}141.0 \\
\mathrm{CH}\end{array}$ & $\begin{array}{l}7.41, \text { dd } \quad(15.0, \\
11.5)\end{array}$ \\
\hline 6 & $\begin{array}{l}132.9, \\
\mathrm{CH}\end{array}$ & $6.50, \mathrm{~m}$ & $\begin{array}{l}132.9 \\
\mathrm{CH}\end{array}$ & $6.50, \mathrm{~m}$ & $\begin{array}{l}133.1 \\
\mathrm{CH}\end{array}$ & $7.08, \mathrm{~m}$ \\
\hline 7 & $\begin{array}{l}139.3, \\
\mathrm{CH}\end{array}$ & $\begin{array}{l}6.66 \text {, dd }(15.0, \\
11.5)\end{array}$ & $\begin{array}{l}139.6 \\
\mathrm{CH}\end{array}$ & $\begin{array}{l}6.65 \text {, dd (15.0, } \\
11.5)\end{array}$ & $\begin{array}{l}137.3 \\
\mathrm{CH}\end{array}$ & $\begin{array}{l}7.21 \text {, dd (14.5, } \\
11.5)\end{array}$ \\
\hline 8 & $\begin{array}{l}133.6, \\
\mathrm{CH}\end{array}$ & $6.45, \mathrm{~m}$ & $\begin{array}{l}133.2, \\
\mathrm{CH}\end{array}$ & $6.45, \mathrm{~m}$ & $\begin{array}{l}130.9 \\
\mathrm{CH}\end{array}$ & $\begin{array}{l}6.94, \mathrm{dd}(15.0, \\
11.5\end{array}$ \\
\hline 9 & $\begin{array}{l}136.9, \\
\mathrm{CH}\end{array}$ & $\begin{array}{l}6.54, \text { dd }(15.0 \text {, } \\
11.0\end{array}$ & $\begin{array}{l}137.3 \\
\mathrm{CH}\end{array}$ & $\begin{array}{l}6.53, \text { dd }(15.0 \text {, } \\
11.0\end{array}$ & $\begin{array}{l}135.1 \\
\mathrm{CH}\end{array}$ & $6.60, \mathrm{~m}$ \\
\hline 10 & $\begin{array}{l}134.7 \\
\mathrm{CH}_{2}\end{array}$ & $6.41, \mathrm{~m}$ & $\begin{array}{l}133.1, \\
\mathrm{CH}\end{array}$ & $6.41, \mathrm{~m}$ & $\begin{array}{l}35.4 \\
\mathrm{CH}_{2}\end{array}$ & $3.68, \mathrm{~m}$ \\
\hline 11 & $\begin{array}{l}133.4 \\
\mathrm{CH}\end{array}$ & $\begin{array}{l}5.75 \text {, dd (15.0, } \\
7.5)\end{array}$ & $\begin{array}{l}133.2 \\
\mathrm{CH}\end{array}$ & $\begin{array}{l}6.36 \text {, dd (15.0, } \\
7.5)\end{array}$ & $\begin{array}{l}131.4, \\
\mathrm{CH}\end{array}$ & $\begin{array}{l}6.86 \text {, dd (11.0, } \\
6.0)\end{array}$ \\
\hline 12 & $85.7, \mathrm{CH}$ & $3.53, \mathrm{~m}$ & $\begin{array}{l}131.9 \\
\mathrm{CH}\end{array}$ & $6.15, \mathrm{~m}$ & $\begin{array}{l}\text { 130.3, } \\
\mathrm{CH}\end{array}$ & $6.41, \mathrm{~m}$ \\
\hline 13 & $\begin{array}{l}37.0 \\
\mathrm{CH}_{2}\end{array}$ & $2.18, \mathrm{~m}$ & $\begin{array}{l}135.1, \\
\mathrm{CH}\end{array}$ & $\begin{array}{l}5.77, \mathrm{dd}(15.0, \\
7.5)\end{array}$ & $\begin{array}{l}35.4 \\
\mathrm{CH}_{2}\end{array}$ & $3.51, \mathrm{~m}$ \\
\hline 14 & $\begin{array}{l}128.6, \\
\mathrm{CH}\end{array}$ & $5.50, \mathrm{~m}$ & $\begin{array}{l}36.2 \\
\mathrm{CH}_{2}\end{array}$ & $2.79, \mathrm{~m}$ & $\begin{array}{l}128.7 \\
\mathrm{CH}\end{array}$ & $\begin{array}{l}6.19 \text {, dd (11.0, } \\
6.0)\end{array}$ \\
\hline 15 & $\begin{array}{l}127.3, \\
\mathrm{CH}\end{array}$ & $\begin{array}{l}5.47, \mathrm{dd}(11.0, \\
7.0)\end{array}$ & $\begin{array}{l}129.5 \\
\mathrm{CH}\end{array}$ & $5.44, \mathrm{~m}$ & $\begin{array}{l}125.5 \\
\mathrm{CH}\end{array}$ & $6.20, \mathrm{~m}$ \\
\hline 16 & $\begin{array}{l}18.0 \\
\mathrm{CH}_{3}\end{array}$ & $1.62, \mathrm{~d}(7.0)$ & $\begin{array}{l}126.7 \\
\mathrm{CH} \\
17.3 \\
\mathrm{CH}_{3} \\
\end{array}$ & $\begin{array}{l}5.45 \text {, dd (11.0, } \\
7.0) \\
1.63, \mathrm{~d}(7.0)\end{array}$ & $\begin{array}{l}17.0 \\
\mathrm{CH}_{3}\end{array}$ & $2.42, \mathrm{~d}(7.5)$ \\
\hline
\end{tabular}

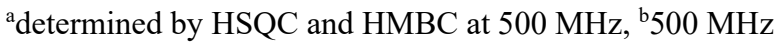

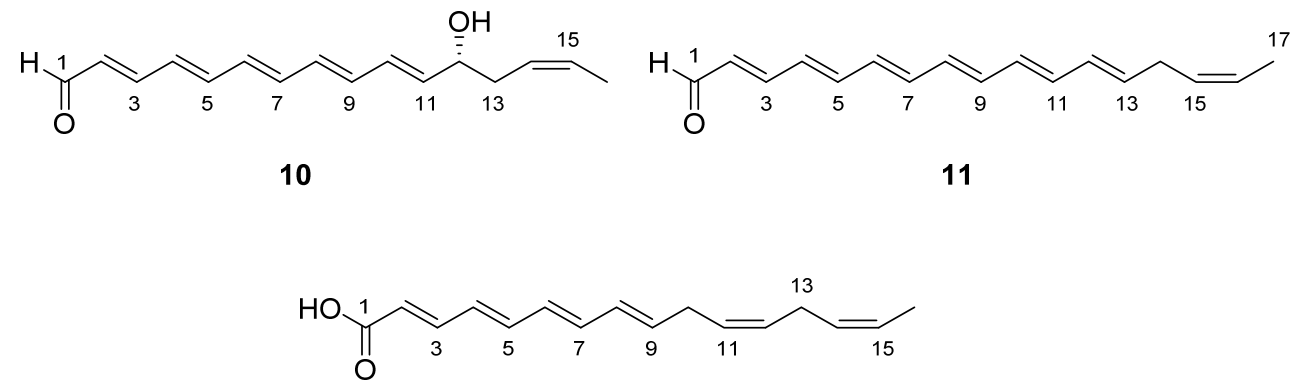


Figure S1. Comparative HPLC-MS profiles of the supernatants of DW503 (black trace), WM1 (red), ORG7 (blue), and ORG6 (gray). The brackets at $\sim 10$ min and 19 min mark peaks corresponding to bactobolins and HMQs, respectively. The starred peak is HMNQ (4hydroxy-3-methyl-2-(2-nonenyl)-quinoline). Strains ORG2 and ORG7 produce thailandene but exhibit lowered synthesis of malleilactone A (Fig. 5), bactobolins, and HMQs.

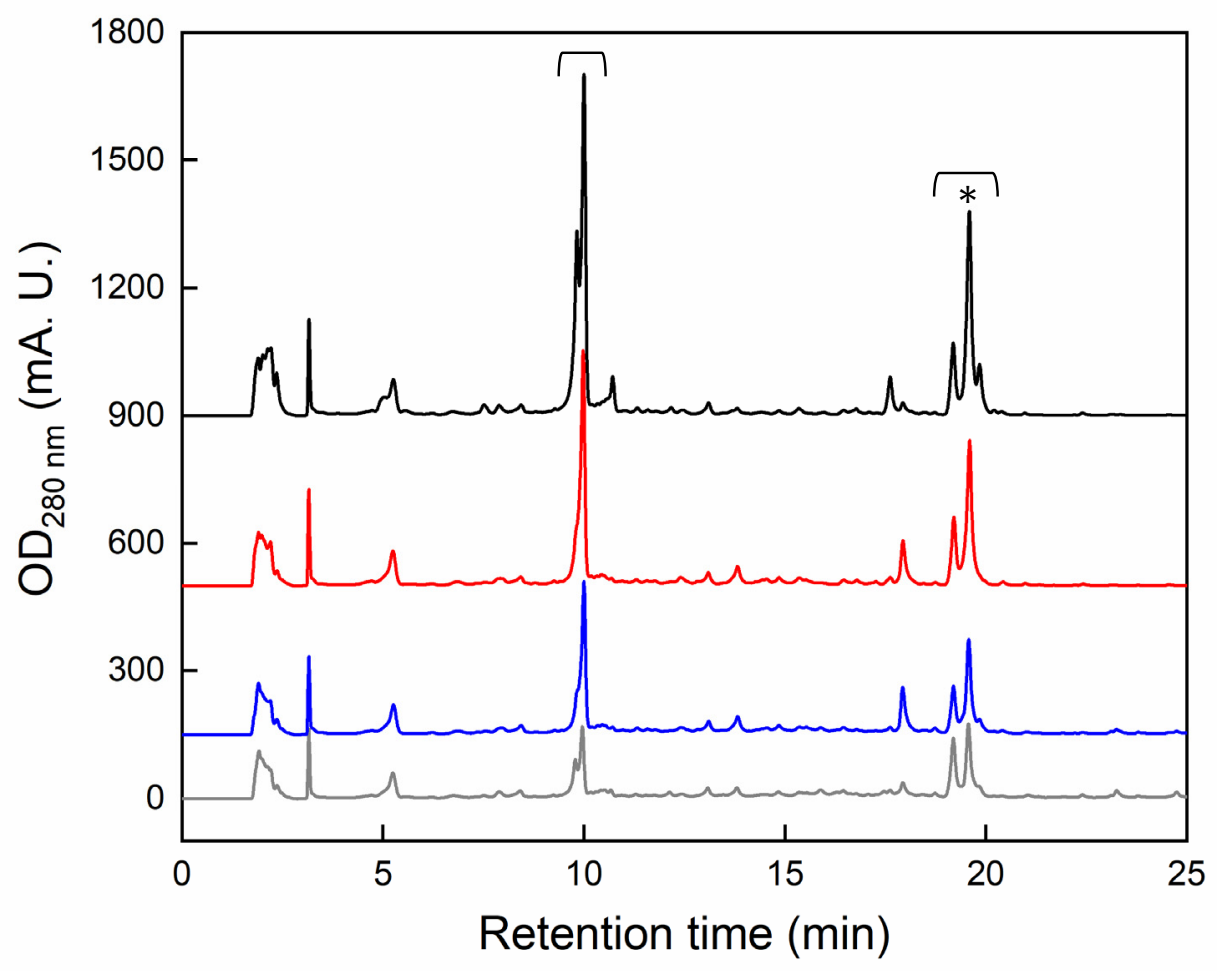


Figure S2. NMR analysis of thailandene A (10). Shown are ${ }^{1} \mathrm{H}$ (top), HSQC (middle left), COSY (middle right), TOCSY (bottom left) and HMBC (bottom right) spectra acquired at $500 \mathrm{MHz}$ in acetone- $d_{6}$ (see Table S5).
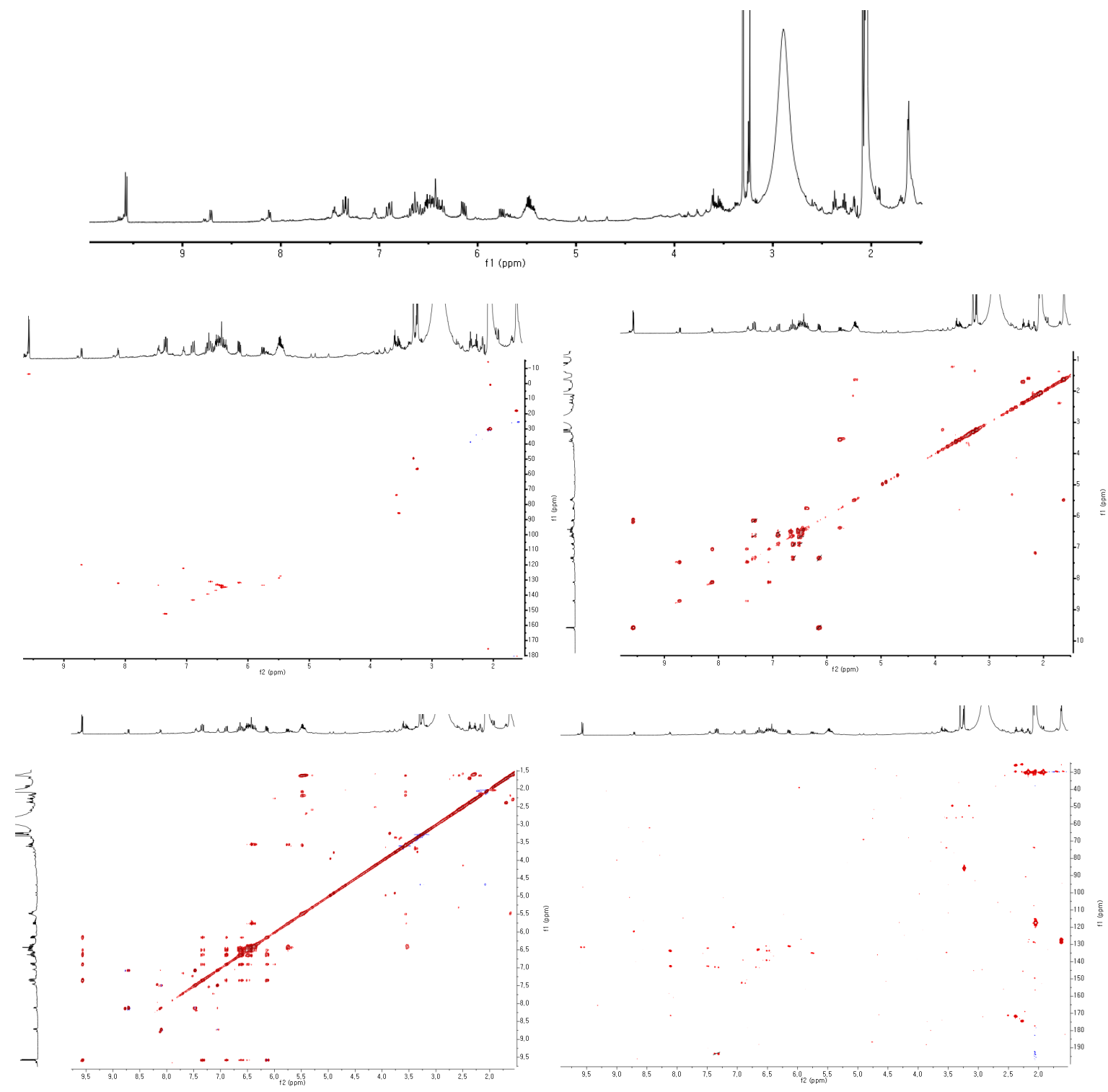

Figure S3. Structure of the thailandene A-MTPA ester annotated with $\Delta \delta$ s- $R$ values. The shifts indicate the $\mathrm{C}-12$ position is $R$-configured.

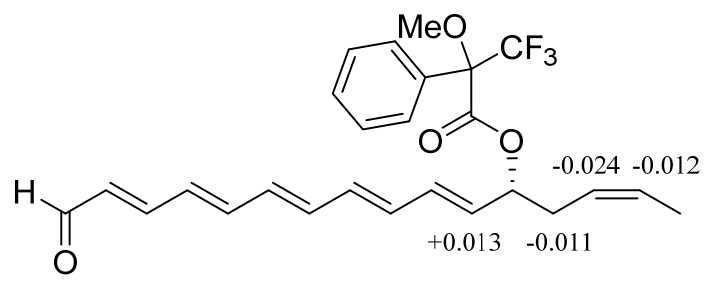


Figure S4. NMR analysis of thailandene B (11). Shown are ${ }^{1} \mathrm{H}$ (top), HSQC (middle left), COSY (middle right), TOCSY (bottom left) and HMBC (bottom right) spectra acquired at $500 \mathrm{MHz}$ in acetone- $d_{6}$ (see Table S5).

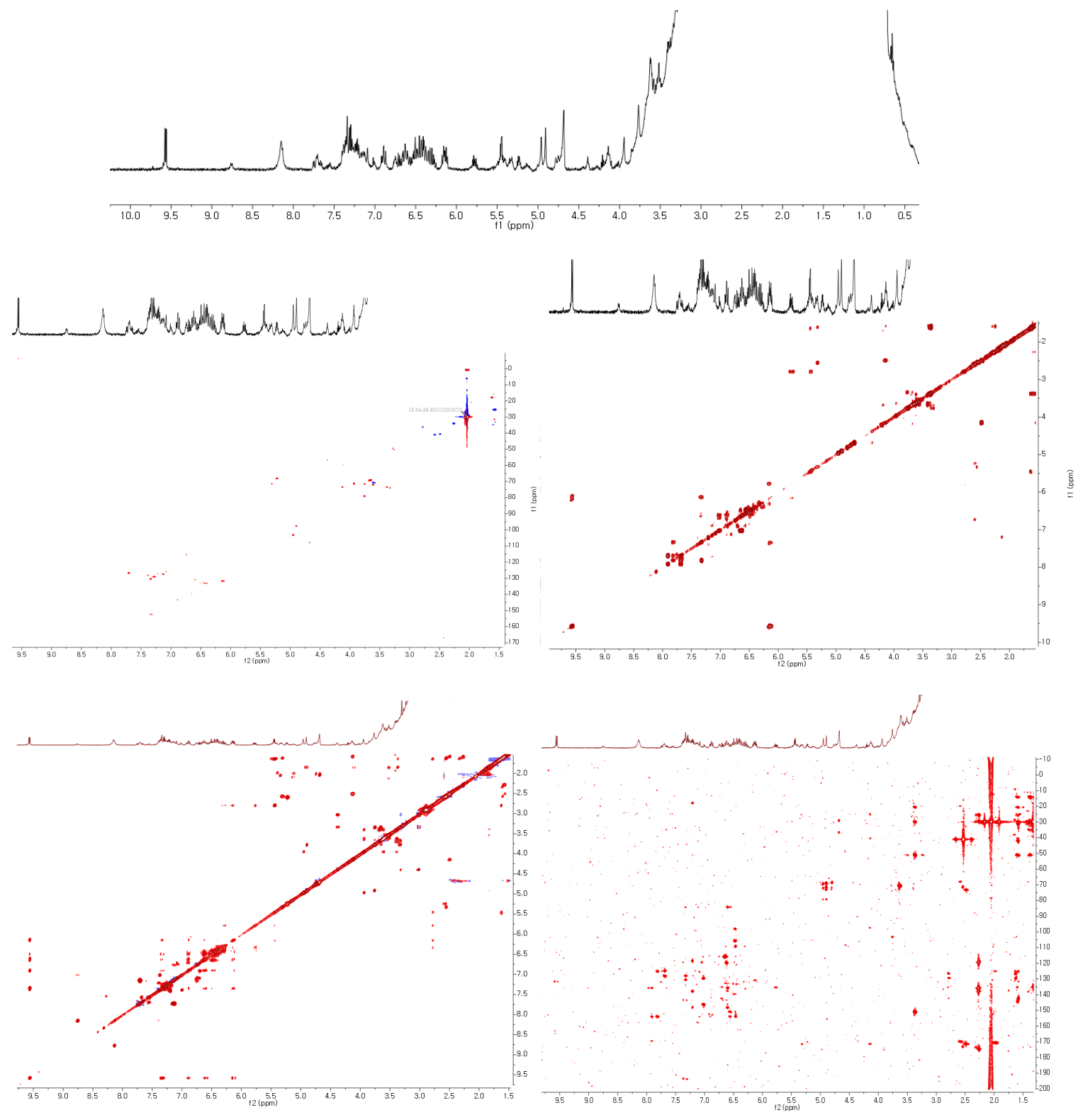


Figure S5. UV-vis spectrum of thailandene B. A broad absorption band and a $\lambda_{\max }$ of $422 \mathrm{~nm}$ is observed.

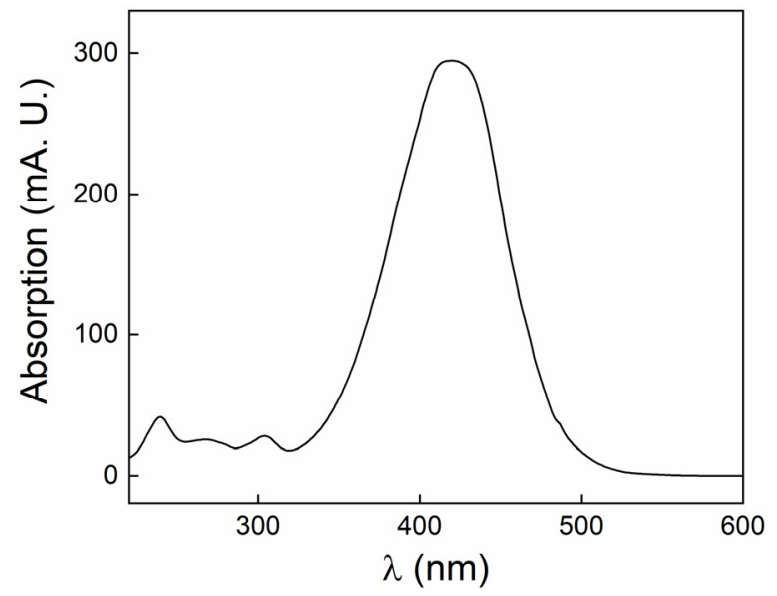


Figure S6. NMR analysis of thailandene C (12). Shown are ${ }^{1} \mathrm{H}$ (top), HSQC (middle left), COSY (middle right), TOCSY (bottom left) and HMBC (bottom right) spectra acquired at $500 \mathrm{MHz}$ in acetone- $d_{6}$ (see Table S5).

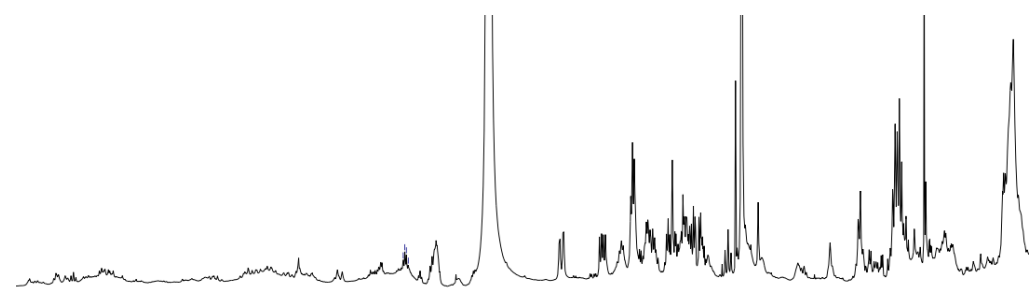

\begin{tabular}{lllllllllllllllllllllllllllllllllllllll}
\hline 8.6 & 8.4 & 8.2 & 8.0 & 7.8 & 7.6 & 7.4 & 7.2 & 7.0 & 6.8 & 6.6 & 6.4 & 6.2 & 6.0 & 5.8 & 5.6 & 5.4 & 5.2 & 5.0 & 4.8 & 4.6 & 4.4 & 4.2 & 4.0 & 3.8 & 3.6 & 3.4 & 3.2 & 3.0 & 2.8 & 2.6 & 2.4
\end{tabular}
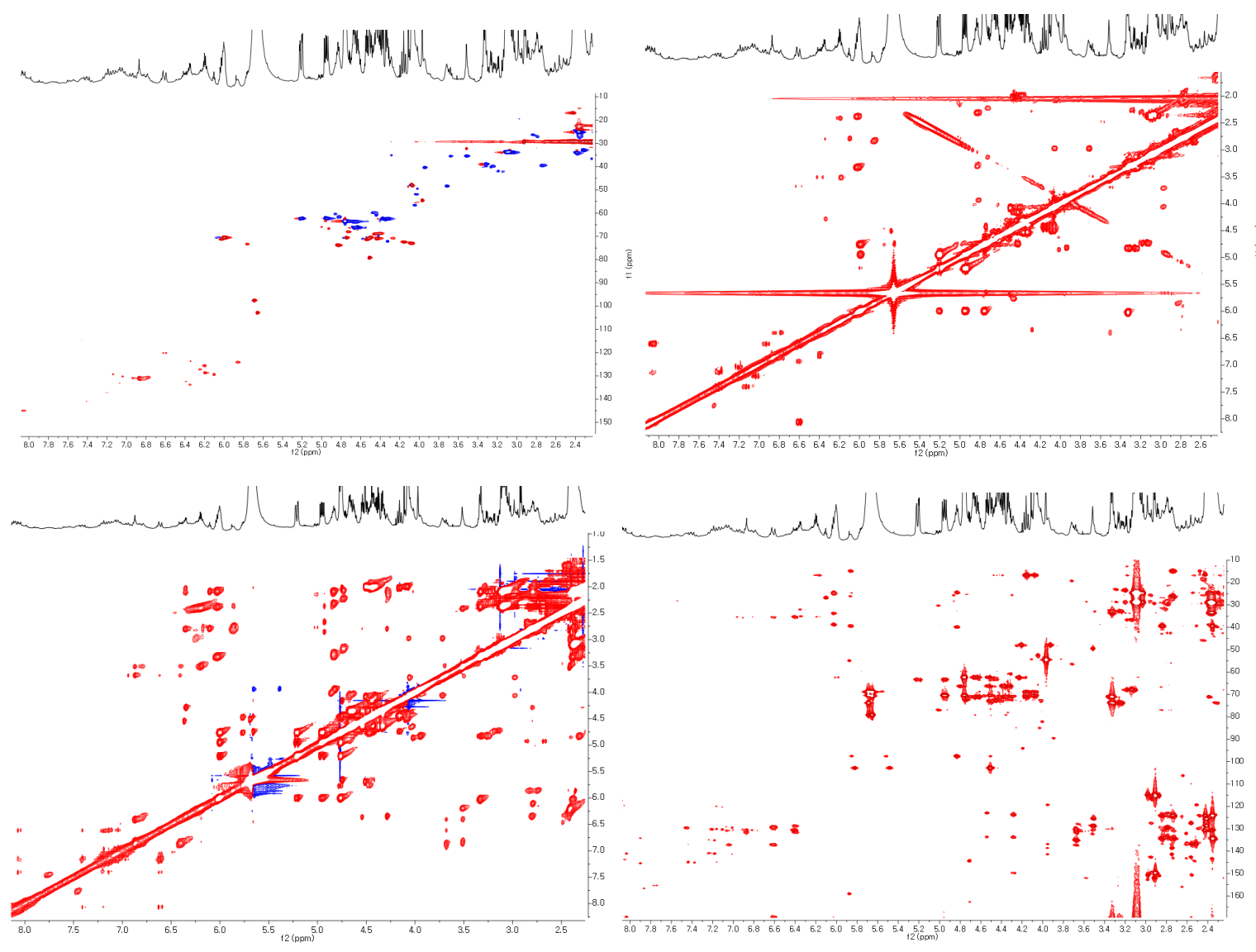

S18 
Figure S7. Thailandene B exhibits strong antimicrobial properties. Shown are growthinhibition assays against $S$. aureus (blue), S. cerevisiae (red), and E. coli (black). The data were fit to a dose-response curve yielding the $\mathrm{IC}_{50}$ or $\mathrm{EC}_{50}$ values shown in Table 1 . The data represent the means $\pm \mathrm{SD}$ of two independent measurements.

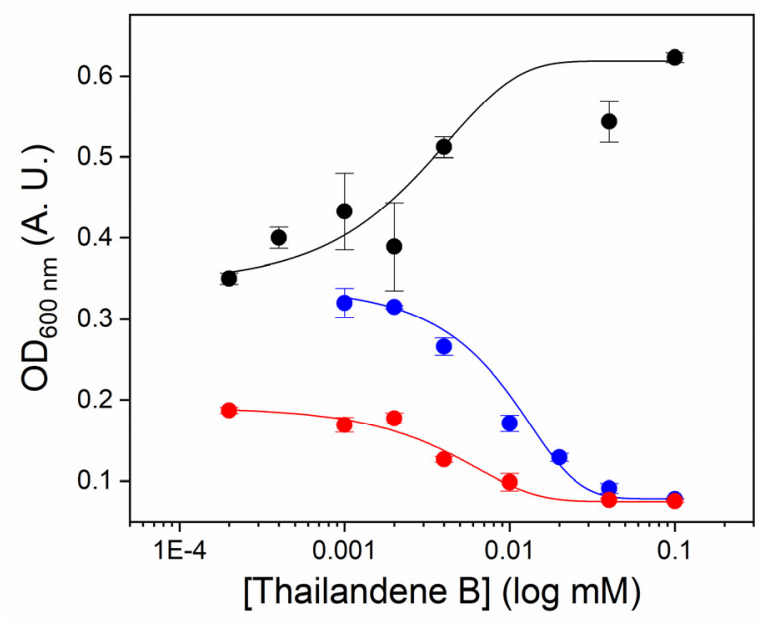


Figure S8. The org cluster is conserved in the Pseudomallei group pathogens. The locus tags BTH_II2349-II2337 (B. thailandensis E264, Bt), BPSS2329-2317 (B. pseudomallei K96243, Bp) and BMAA2090-2077 (B. mallei ATCC 23344, Bm) were submitted to the mVISTA server, aligned with LAGAN using default parameters $(70 \% / 100 \mathrm{bp}$ conservation, 100-bp calculation window), and visualized with the Bt sequence as a reference for comparison. The Bt $\operatorname{org} A-\operatorname{org} M$ genes are shown as arrows above the aligned sequences and the nucleotide coordinates are shown below in kilobases $(\mathrm{K})$. The pink graphics represent the percent conservation between the aligned sequences at a given coordinate; the $\%$ nucleotide identity is shown on the right axis.
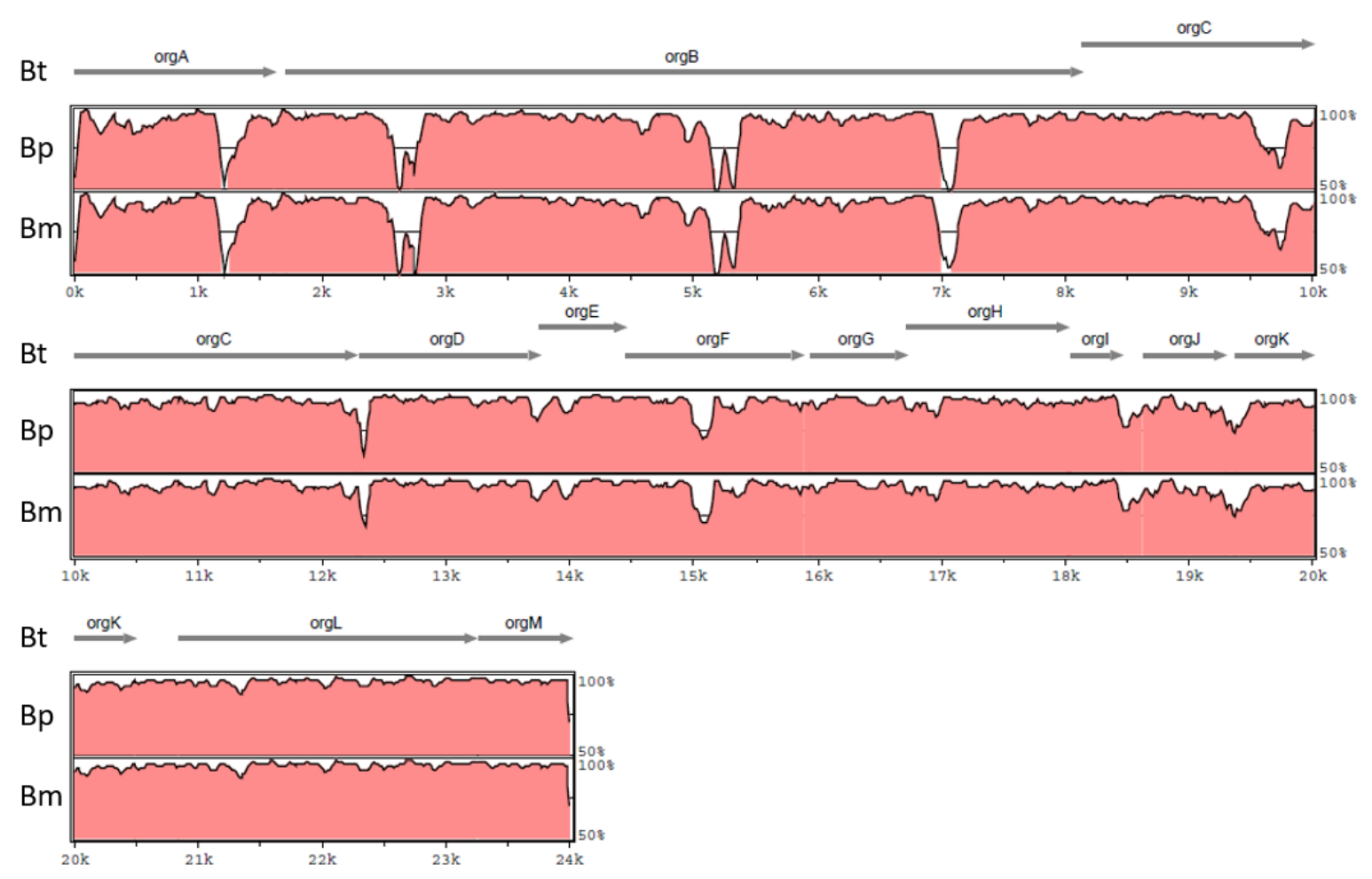


\section{SI References}

1) Wilson, K. (2001) Preparation of genomic DNA from bacteria. Curr. Protoc. Mol. Biol. 56, 2.4.1-2.4.5.

2) Yu, Y., Kim, H. S., Chua, H. H., Lin, C. H., Sim, S. H., Lin, D., Derr, A., Engels, R., DeShazer, D., Birren, B., Nierman, W. C., and Tan, P. (2006) Genomic patterns of pathogen evolution revealed by comparison of Burkholderia pseudomallei, the causative agent of melioidosis, to avirulent Burkholderia thailandensis. BMC Microbiol. 6, 46 BMC Microbiol. 6, 46.

3) Saeed, A. I., Sharov, V., White, J., Li, J., Liang, W., Bhagabati, N. et al. (2003) FM4: a free, open-source system for microarray data management and analysis. Biotechniques 34, 374-378

4) Wiśniewski, J. R., and Gaugaz, F. Z. (2015) Fast and sensitive total protein and peptide assays for proteomic analysis. Anal. Chem. 87, 4110-4116.

5) Hughes, C. S., Foehr, S., Garfield, D. A., Furlong, E. E., Steinmetz L. M., and Krijgsveld, J. (2014) Ultrasensitive proteome analysis using paramagnetic bead technology. Mol. Syst. Biol. 10, 757.

6) Hoye, T. R., Jeffrey C. S., and Shao, F. (2007) Mosher ester analysis for the determination of absolute configuration of stereogenic (chiral) carbinol carbons. Nat. Protoc. 2, 2451-2458.

7) Simon, R., Priefer, U., and Pühler, A. (1983) A broad host range mobilization system for in vivo genetic engineering: Transposon mutagenesis in Gram negative bacteria. Bio/Technology 1, 784791.

8) Brett, P. J., DeShazer, D., and Woods, D. E. (1998) Burkholderia thailandensis sp. nov., a Burkholderia pseudomallei-like species. Int. J. Syst. Bacteriol. 48, 317-320.

9) Burtnick, M. N., Bolton, A. J., Brett, P. J., Watanabe D., and Woods, D. E. (2001) Identification of the acid phosphatase (acpA) gene homologues in pathogenic and non-pathogenic Burkholderia spp. facilitates TnphoA mutagenesis. Microbiology 147, 111-120.

10) Pansegrau, W., Lanka, E., Barth, P. T., Figurski, D. H., Guiney, D. G., Haas, D. et al. (1994) Complete nucleotide sequence of Birmingham IncP alpha plasmids. Compilation and comparative analysis. J. Mol. Biol. 239, 623-663.

11) Dennis, J. J., and Zylstra, G. J. (1998) Complete sequence and genetic organization of pDTG1, the 83 kilobase naphthalene degradation plasmid from Pseudomonas putida strain NCIB 9816-4. Appl. Environ. Microbiol. 64, 2710-2715. 